\title{
Comment on "Encouraging a bare minimum while striving for the gold standard: a response to the updated WHO-WFSA guidelines"
}

\author{
Alexander W. Peters, MD • John G. Meara, MD, DMD, MBA • \\ Emmanuel M. Makasa, MD, MPH • Walter D. Johnson, MD, MBA, MPH
}

Received: 3 August 2018/Accepted: 3 August 2018/Published online: 13 December 2018

(C) Canadian Anesthesiologists' Society 2018

\section{To the Editor,}

We greatly appreciate the concerns expressed by Hendel et $a l .{ }^{1}$ in their recent letter addressing the World Health Organization-World Federation of Societies of Anesthesia (WHO-WFSA) standards of the safe conduct of anesthesia. $^{2}$ As surgeons, we strongly support the WHOWFSA guidelines as a critical step towards strengthening surgical systems ${ }^{3}$; more importantly, we support the efforts of anesthesiologists that are needed to make these

This letter is accompanied by a reply. Please see Can J Anesth 2019; 66: this issue.

\author{
A. W. Peters, MD ( $₫)$ \\ Department of Surgery, Weill Cornell Medical College, New \\ York, NY, USA \\ e-mail: awp9003@nyp.org
}

Program in Global Surgery and Social Change, Harvard Medical School, Boston, MA, USA

Department of Plastic and Oral Surgery, Boston Children's Hospital, Boston, MA, USA

J. G. Meara, MD, DMD, MBA

Program in Global Surgery and Social Change, Harvard Medical School, Boston, MA, USA

Department of Plastic and Oral Surgery, Boston Children's Hospital, Boston, MA, USA

E. M. Makasa, MD, MPH

Cabinet Office, Lusaka, Zambia

University of Witwatersrand, Johannesburg, South Africa

W. D. Johnson, MD, MBA, MPH

Emergency and Essential Surgical Care Programme, World Health Organization, Geneva, Switzerland guidelines come to life. While acknowledging the authors' concerns, we would like to offer a slightly different perspective in two regards.

First, the authors state that anesthesiologists are not significantly engaged in National Surgical, Obstetric, and Anesthesia Plan (NSOAP) efforts. Our perspective, having observed several such processes, is that anesthesiologists (and obstetricians) have been viewed as equal partners and collaborators. Global leaders in anesthesia, with the WFSA (which has official relations ${ }^{\mathrm{A}}$ with WHO), spearhead meetings, lead data collection, and frequently communicate about joint efforts. Further, the WHO Emergency and Essential Surgery Programme has always welcomed anesthesia collaboration and has hosted anesthesia interns. In March of 2018, WHO and the Harvard Program in Global Surgery and Social Change cohosted an NSOAP regional workshop in Dubai, which included significant representation from WFSA. ${ }^{4}$

More importantly, however, the NSOAP process has no "owner" per se-all those interested are welcome. All NSOAP resources are open access and publicly available, ${ }^{5}$ including a soon-to-be published NSOAP development manual from WHO. Addressing the inequities in surgery, obstetrics, and anesthesia access will require an "all handson deck" approach; WHA resolution 68.15 (Strengthening Emergency and Essential Surgical Care and Anaesthesia

\footnotetext{
A "Official relations" is a designation granted to certain entities that contribute particular areas of expertise to the work of WHO. This relationship provides the entity with certain privileges, including attending and making statements at governing body meetings, and hosting side events during these meetings. Gaining official relations status is through a systematic vetting process that requires significant collaboration of at least two years with renewal and update every three years (http://www.who.int/about/collaborations/non-stateactors/in-official-relations/en/) (accessed August 3, 2018).
} 
as a Component of Universal Health Coverage $)^{6}$ cannot be realized without the full and equal involvement of the anesthesia community.

Second, the authors expressed concerns that these guidelines are unrealistic for low- and middle-income countries (LMICs). While it is true that some countries cannot immediately meet the WHO-WFSA standards, national health leaders must have clear targets to structure reforms against which to measure progress. The authors' criticisms - that aspirational goals are nice but unrealistic - could be made about several important efforts, including Disease Control Priorities, Third Edition, ${ }^{7}$ the Lancet Commission on Global Surgery, ${ }^{8}$ WHA resolution $68.15,{ }^{6}$ or the entire roster of Sustainable Development Goals. ${ }^{9}$

Such a critique as Hendel et al. espouse ${ }^{1}$ risks marginalizing the value of life in LMICs. All people deserve quality surgical, obstetric, and anesthesia careframed around standards, guidelines and indicators-as components of universal health coverage, which by its very nature is an aspirational goal. We acknowledge that this requires a dramatic, if not unprecedented, scaling-up of "staff, stuff, space, and systems" to meet quality expectations. Together, in solidarity with our anesthesia colleagues, we need to vow to challenge the "soft bigotry of low expectations" 10 in global surgery and anesthesia.

Disclaimer The views expressed herein are those of the authors and do not reflect the views of their affiliated organizations.

Conflict of interest Dr. John G. Meara receives grant support from the GE Foundation.

Editorial responsibility This submission was handled by Dr. Hilary P. Grocott, Editor-in-Chief, Canadian Journal of Anesthesia.

\section{References}

1. Hendel S, Banguti P, Workneh RS, et al. Encouraging a bare minimum while striving for the gold standard: a response to the updated WHO-WFSA guidelines. Can J Anesth 2018; DOI: https://doi.org/10.1007/s12630-018-1209-9.

2. Gelb AW, Morriss WW, Johnson W, et al. World Health Organization-World Federation of Societies of Anaesthesiologists (WHO-WFSA) International Standards for a Safe Practice of Anesthesia. Can J Anesth 2018; 65: 698-708.

3. World Health Organization. Surgical Care Systems Strengthening: Developing National Surgical, Obstetric and Anaesthesia Plans; 2017. Available from URL: http://www. who.int/surgery/publications/scss/en/ (accessed August 2018).

4. Program in Global Surgery and Social Change - Harvard Medical School. National Surgical, Obstetric, and Anaesthesia Workshop, March 21-22, 2018 - Dubai, UAE. Available from URL: https://www.pgssc.org/dubai-nsoap-workshop (accessed August 2018).

5. Program in Global Surgery and Social Change - Harvard Medical School. National Surgical, Obstetric and Anesthesia Planning. Available from URL: https://www.pgssc.org/nationalsurgical-planning (accessed August 2018).

6. World Health Organization. World Health Assembly Resolution 68.15: Strengthening Emergency and Essential Surgical Care and Anaesthesia as a Component of Universal Health Coverage; 2015. Available from URL: http://apps.who.int/gb/ebwha/pdf_ files/WHA68/A68_R15-en.pdf (accessed August 2018).

7. Debas HT, Donkor P, Gawande A, Jamison DT, Kruk ME, Mock $C N$. Disease Control Priorities, Third Edition (Volume 1): Essential Surgery. The World Bank; 2015.

8. Meara JG, Leather AJ, Hagander L, et al. Global Surgery 2030: evidence and solutions for achieving health, welfare, and economic development. Lancet 2015; 386: 569-624.

9. United Nations. Sustainable Development Goals. Available from URL: https://www.un.org/sustainabledevelopment/sustainabledevelopment-goals/. Published 2015. (accessed August 2018).

10. Washington Post.com. George W. Bush's Speech to the NAACP, July 10, 2000. Available from URL: https://www. washingtonpost.com/wp-srv/onpolitics/elections/bushtext071000. htm (accessed August 2018). 